SHS Web of Conferences 24, 01001 (2016)

DOI: $10.1051 /$ shsconf/ 20162401001

(c) Owned by the authors, published by EDP Sciences, 2016

\title{
Empirical research on impact of social capital of scientific and technological intermediary on knowledge transfer--Taking the Science and Technology Park of Nanjing University as an example
}

\author{
Yongkang Jiang ${ }^{1,2} \&$ Qiang Mei $^{1}$ \\ ${ }^{1}$ School of Management, Jiangsu University, Zhenjiang, Jiangsu, China \\ ${ }^{2}$ School of Finance and Economics, Zhenjiang College, Zhenjiang, Jiangsu, China
}

\begin{abstract}
The mechanism of the impact of social capital of scientific and technological intermediary on knowledge transfer is not yet clear. This research tries to build a theoretical framework of the social capital of scientific and technological intermediary for the knowledge transfer performance, and also selects the incubators of the Science and Technology Park of Nanjing University as a typical case of the scientific and technological intermediary, analyzes the differences between the social capital of scientific and technological intermediary and the social capital of the government, colleges and universities, enterprises and different subjects of knowledge innovation through open research, and discusses the effect and mechanism of knowledge transfer, so as to clarify the nature of social capital of scientific and technological intermediary, and give play to positive effect in the knowledge transfer and innovation, and provide scientific basis and reference experience.
\end{abstract}

Keywords: scientific and technological intermediary; social capital; knowledge transfer; Science and Technology Park of Nanjing University

\section{INTRODUCTION}

The knowledge transfer is in the central and leading position in the innovation process ${ }^{[1]}$. Henry. Chesbrough researches the important role of external knowledge sources on the innovation process and emphasizes that, besides internal innovation, the enterprise also needs to acquire fresh knowledge from colleges and universities, scientific research institutes and other enterprises, thereby generating the knowledge transfer. In addition, he also points out that there are many difficulties in the process of knowledge transfer, that is, knowledge stickiness; he also researches the factors of knowledge stickiness induced by knowledge sources, knowledge acceptors, knowledge content and transfer situations ${ }^{[2]}$. In fact, it is difficult to deal with the knowledge stickiness which only replies on the demander and supplier of the knowledge transfer and induced in the process of knowledge transfer. However, relying on the professional knowledge, technology, network and social capital, the scientific and technological intermediary provides intermediary services for the knowledge suppliers and demanders, thus playing a positive role in promoting the process of knowledge transfer process, improving knowledge transfer performance, and reducing and eliminating factors of inducing knowledge stickiness. Howells proposes that the scientific and technological intermediary is a bridge between the knowledge suppliers and demanders, which can overcome obstacles of the suppliers and demanders in the information, management, culture, cognition and other aspects in the process of knowledge transfer ${ }^{[3]}$; Hoppe and Odzneorne consider that the scientific and technological intermediary can reduce the problems of uncertainty in the technical transactions between the university researchers and enterprises, as well as the adverse selection ${ }^{[4]}$. Specific to the scientific and technological intermediary, its social capital position becomes an important factor of affecting the knowledge transfer performance, which is linked with the social capital of colleges and universities, scientific research institutions and enterprises, thus opening up transfer channels for the knowledge suppliers and demanders, and smoothly realizing the knowledge transfer. However, under the same condition, there are 
also differences in the social capital of the scientific and technological intermediary, so it has different impacts on the knowledge transfer ${ }^{[5]}$. Currently, the education circles are more concerned about the impact of the enterprise's social capital on the knowledge transfer ${ }^{[6]}$. Through research, Levine and others find that, in the process of technological innovation, the enterprise's social contact is helpful for acquisition, transfer, integration and creation of external knowledge, and the enterprises reduce doubts and increase trust between both parties of transaction through various kinds of contract, thus gaining valuable knowledge ${ }^{[7]}$; the high level of trust reduces the costs of supervision and negotiation in the process of performance of knowledge transfer contract ${ }^{[8]}$, but the nature and function of the enterprise and the scientific and technological intermediary is different, and the social capital is also quite different, so it is very necessary to research the impact on the knowledge transfer. However, the current theoretical exploration and empirical research on the social capital of the scientific and technological intermediary carried out by domestic and foreign scholars are relatively weak, especially in analysis of the effect and mechanism of social capital differences between the scientific and technological intermediary and different subjects of knowledge innovation on the knowledge transfer. Therefore, by selection of typical cases of the scientific and technological intermediary, this paper tries to build a theoretical framework of the social capital of scientific and technological intermediary for the knowledge transfer performance, explores the differences of social capital between the scientific and technological intermediary and different subjects of knowledge innovation, and carries out in-depth analysis of the effect and mechanism on the knowledge transfer, so as to clarify the nature of social capital of scientific and technological intermediary, and give play to positive effect of the scientific and technological intermediary on the process of knowledge transfer, and provides scientific basis and reference experience to reduce negative effects induced by knowledge stickiness.

2 ORETICAL FRAMEWORK OF THE IMPACT OF SOCIAL CAPITAL OF SCIENTIFIC AND TECHNOLOGICAL INTERMEDIARY ON THE KNOWLEDGE TRANSFER

\subsection{Social capital of scientific and technological intermediary}

Currently, there is not a final conclusion on the concept of scientific and technological intermediary in the education circles. Many foreign scholars view the scientific and technological intermediaries as innovation intermediaries from the perspective of innovation and knowledge transfer. For example, Howells points out that the scientific and technological intermediary is a node to be engaged in the technology and knowledge brokering activities, and promoting innovation networks and innovation systems of the technology transfer ${ }^{[3]}$; Smedlund defines the scientific and technological intermediary as a functional organization located between the knowledge producers and users ${ }^{[9]}$. For China, the Ministry of Science and Technology issued On Opinions of Vigorously Developing Scientific and Technological Intermediary in 2002 , of which the scientific and technological intermediary is defined as an organization "to carry out technical diffusion, achievement transformation, technology assessment, allocation of innovation resources, innovation decision-making, and management consulting and other professional services for the society". Therefore, integrated with the domestic and foreign research achievements, this research defines the scientific and technological intermediary as an important organization to provide intermediary services for the knowledge suppliers and demanders and effectively realize the knowledge transfer and innovation relying on the professional knowledge, technology, network and social capital from the perspective of the innovation and knowledge transfer.

In terms of the social capital of the scientific and technological intermediary and by reference of the research content of Inkpen and Tsang, this paper carries out analysis from three aspects, namely, structural dimension, relationship dimension and cognitive dimension ${ }^{[10]}$. Specifically speaking, the structural dimension refers to an overall pattern of the connection between actors, including the network relation, network structure and network stability. Among them, the network relation mainly refers to the connection between actors in the network, which is a basis of social capital and a link between the relevant organizations and individuals, and creates opportunities for interaction between actors; the network structure refers to the network density, grade and connectivity features, which affects the flexibility and complexity of knowledge transfer in the network; network stability mainly refers to the frequency of replacing network members. The relationship dimension refers to the direct relation nature between actors such as trust and so on. The cognitive dimension refers to shared vision and shared culture of the network members.

\subsection{Knowledge transfer approach by social capital}

Many researches show that the social capital plays a positive facilitation role in the knowledge transfer. The closer the relationship between the enterprise and the external organization is, the more opportunities to learn and acquire knowledge are, and the stronger the absorptive capacity is. The relationship dimension of the social capital affects the knowledge transfer motivation, while the cognitive dimension affects the knowledge transfer capacity ${ }^{[11]}$; the shared vision and 


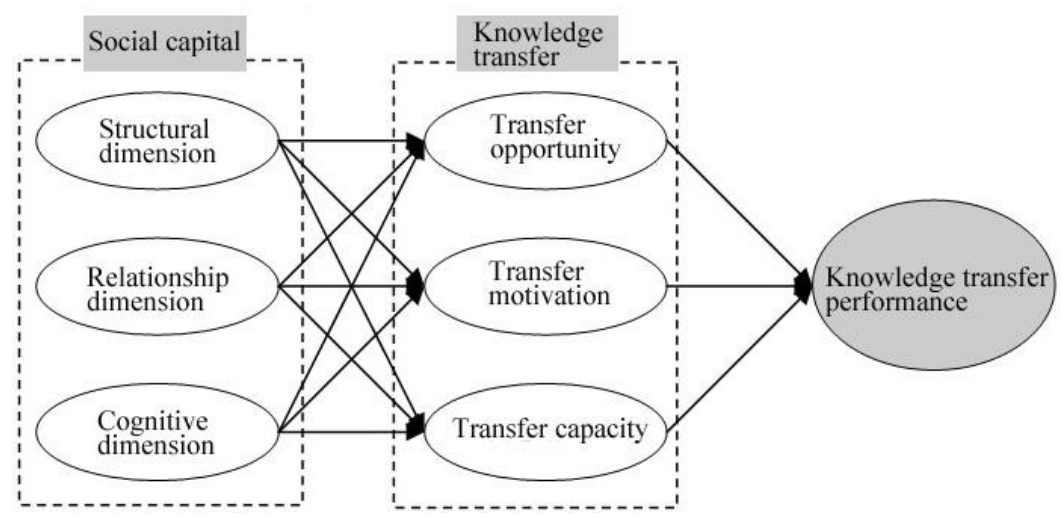

Figure 1. Theoretical framework of the social capital of scientific and technological intermediary for the knowledge transfer performance (model).

the same organizational culture will make both parties of knowledge transfer desire to share knowledge, promote the exchange of knowledge and improve the knowledge absorptive capacity ${ }^{[12]}$.

The social capital mainly affects the knowledge transfer performance through three ways, namely, transfer opportunity, transfer motivation and transfer capacity ${ }^{[13]}$. Specifically speaking, the transfer opportunity refers to the complexity of searching knowledge sources and quantity of transfer channels ${ }^{[14]}$. The richer the enterprise's social capital is, the more channels to acquire knowledge are, the lower the difficulty in searching knowledge sources is, and the easier to realize knowledge transfer is; the transfer includes the motivation of both parties of knowledge transfer, that is, the will of transferring knowledge sources and reception motivation of knowledge acceptors, of which the motivation and will of both parties of knowledge transfer affect the quantity and quality of the knowledge transfer; the transfer capacity includes the imparting capacity of the knowledge sources and absorptive capacity of acceptors. The stronger the imparting capacity and the absorptive capacity are, the better the effect of knowledge transfer is.

\subsection{Theoretical framework}

Based on the above analysis, this research tries to build a theoretical framework of the social capital of scientific and technological intermediary for the knowledge transfer performance (Figure 1), carries out research of the social capital of scientific and technological intermediary from three aspects, namely, structural dimension, relationship dimension and cognitive dimension, and explores the differences of knowledge transfer performance due to the differences in the transfer opportunity, transfer motivation and transfer capacity, thus laying a foundation for exploration of the effect and mechanism of the social capital of scientific and technological intermediary on the knowledge transfer.

\section{CASE SELECTION AND DATA COLLECTION}

\subsection{Case selection}

From the perspective of innovation and knowledge transfer, the relevant scientific and technological intermediaries mainly include the technology transfer centers, technology exchanges, technology business incubators, engineering and technology research centers. The technology business incubator is a typical intermediary that can help the enterprise to strengthen industry-university-research cooperation and promote capacity for independent innovation ${ }^{[15]}$ with the carriers of science and technology entrepreneur services to promote the transformation of scientific and technological achievements, and cultivate new high-tech enterprises. Therefore, this research selects the technology business incubator as a representative of the scientific and technological intermediary, and the Nanjing University-National University Science and Technology Park of University Cluster in Gulou District (hereinafter referred to as Science and Technology Park of Nanjing University) as a research object. The Science and Technology Park is co-sponsored by Nanjing University and the People's Government in Gulou District of Nanjing City, and co-founded by Hohai University, China Pharmaceutical University, Nanjing Normal University and so on with a total of eight colleges and universities in Gulou District, which is integrated with research and development, incubation, technology trade and transformation of scientific research achievement. In this district, there are 20 colleges and universities, more than 10 national key laboratories, 58 scientific research institutes and 42 academicians. With the organization pattern of "nine schools and one government" and the innovative system combined with the "policy, industry, university, scientific research and finance", it effectively links up with complementary resources of the government, colleges and universities, scientific research institutions, enterprises and markets, and forms an entrepre- 
neurship center on Qingdao Road, a Patent Entrepreneurship Park, a Yifa Entrepreneurship Park, a Suning Entrepreneurship Park and various characteristic entrepreneurship parks; in April, 2005, it became China's first batch of "the service organization of entrepreneurship projects of small and medium-sized enterprise technology innovation funds in the Ministry of Science and Technology"; in November, 2006, it passed the qualification review of the national technology business incubators. It fosters the electric power automation, communication research and development, software development, biological medicine, new chemical materials and a number of characteristic industrial clusters, and has a higher status and influence in Jiangsu Province and even the whole nation. Integrated with the research and development, incubation and achievement transformation, the park has a very complete knowledge transfer chain, which is an ideal research object.

\subsection{Data collection}

This research adopts an open questionnaire and in-depth interviews, and selects general staff and senior managers of the incubator (hereinafter referred to as the incubator) enterprise of the Science and Technology Park of Nanjing University for in-depth interviews, and obtains the first-hand information. A total of 35 staffs and 19 general staffs are interviewed, accounting for $54.29 \%$; 16 senior managers, accounting for $45.71 \%$. Each interview takes about 60 to 120 minutes and adopts the interview record chat to record keywords and sentences. The main problems of the interviews are as follows: What are network organization members in the incubator enterprise? What is the situation of relations between the network organization members, density, frequency of communication, trust, shared vision and shared culture? How does the incubator establish a relation network? What is the role of trust of network organization members in the knowledge transfer? How does the incubator establish a trust relationship with the network organization members? What is the role of shared vision and shared culture in the knowledge transfer? How to form a common vision and shared culture with the network members? What is the impact of the incubator social capital on the knowledge transfer opportunities, receiving motivation and absorptive capacity? How to affect?

\section{EMPIRICAL RESEARH ON THE IMPACT OF SOCIAL CAPITAL OF SCIENTIFIC AND TECHNOLOGICAL INTERMEDIARY ON KNOWLEDGE TRANSFER}

Through open investigations and in-depth interviews, this paper has a more concrete understanding of the social capital of knowledge transfer of the incubator, and summarizes the situation and characteristics of the social capital of scientific and technological intermediary, and its effect and mechanism on the knowledge transfer based on three dimensions, namely, structure, relation and cognition of the social capital.

\subsection{Social capital position of the scientific and technological intermediary}

\subsubsection{Structural dimension}

(1) Network relation

The Science and Technology Park of Nanjing University implements the management mode of "nine schools and one government". The government provides planning guidance for the Science and Technology Park, and takes the lead to coordinate work among colleges and universities, which plays a role of "binder", and also provides the incubators, scientific research institutions and entrepreneurship enterprises with the financial support, tax deduction and exemption, sites and other services, which is also in a dominant position in the network. The colleges and universities, scientific research institutions and incubators are located in the area which is the same with the incubated enterprises. Both of them have a very close relation at the organizational level and frequent interaction. The incubator plays a "hub" role in network nodes, which links together with the relevant organizations to expand the whole social capital network of the park and enhance network relation strength.

\section{(2) Network construction}

In the Science and Technology Park, there are 20 colleges and universities and 58 scientific research institutes, many of which are research and development institutions in Fortune 500 Enterprise; as knowledge producers, numerous start-ups, colleges and universities and scientific research institutes are knowledge sources of the knowledge transfer; the science and technology enterprise is a knowledge demander; in addition to the link between the demander and the supplier, the incubator can provide both parties with information communication, technology consulting and other in-depth services, which links up with the network members, including the government, and forms a relation network with a very great density. The contact between network members is close, the network connectivity is very good, and knowledge mobility in the network is better. The organizational members in the network are independent with each other, so the network is free of hierarchy.

\section{(3) Network stability}

The colleges and universities and government in the Science and Technology Park have the best stability, which are long-standing as organizations although with some personnel changes, and conducive to establishing a long-term stable cooperative relationship 
between the incubators and the colleges and universities and government.

Most of the scientific research institutions in the park are established with a better stability by large enterprises or colleges and universities. The incubators are typically established by the government or supported by the government, but they have a better stability as enterprises to face the market competition. Due to its weak strength and management, the incubated enterprises have a relatively high probability of failure and elimination facing with the fierce market competition. Moreover, once graduation, the incubated enterprises must vacate and reduce network relation due to the geographical distance. New enterprises will replace the original enterprises with a higher replacement rate and worse stability.

\subsubsection{Relationship dimension}

Trust is the core content of the relationship dimension in the social capital of scientific and technological intermediary. The Science and Technology Park of Nanjing University adopts co-building mode led by Nanjing University and the government in Gulou District; Nanjing University has a high reputation and influence as the most famous institution of higher education in Jiangsu, which is prone to obtain the trust of other organizational members in the network; the government provides great support in the establishment and management of the Science and Technology Park with a high degree of trust as well. From the analysis of survey results, the credibility between the network members is out of balance; the credibility between the incubators and the government and enterprises is the highest; the credibility between incubators and universities is somewhat high; the credibility between incubators and the scientific research institutes is the worst. The main reason for the imbalanced credibility is the difference in the relation strength between the incubators and the network organizations. Due to encouraging innovation-driven strategies, the government provides great support for the construction of incubators, and both of them have a close relation; the incubated enterprise is relatively weak from technology to management, which can grow up and expand by relying on the support and help of the incubator, just like the relationship between parents and infants with a very high credibility. The colleges and universities and the scientific research institutions generally have a relatively strong strength, and strong dependence, they have less communication and relatively low credibility with the incubator than with government and enterprise.

\subsubsection{Cognitive dimension}

(1) Shared vision

The shared vision is helpful for both parties to establish a good cooperation relationship. The visions of the colleges and universities, scientific research insti- tutions and enterprises in the Science and Technology Park are completely different, which are mainly due to the attitude in the treatment of scientific research achievements. Many scientific researches in the colleges and universities aim at conferring academic titles and subject projects and paying more emphasis on the advancement of scientific research achievements, but paying less emphasis on the technological achievement transformation; however, the scientific research institutions pay more emphasis on the practicality and commercialization transformation of scientific research achievements than that of colleges and universities. The enterprise thinks highly of the commercialization and economic benefits of the scientific research achievements. In order to better integrate and cooperate with the network members, the incubators need to coordinate with the vision of each party, fully understand the goals and aspirations of each party, establish common goals of each party based on the maximum common ground, carry out good cooperation and promote smooth knowledge transfer.

\section{(2) Shared culture}

The core of culture is the value. The difference in the organization values may lead to the difference in the code of conduct. Too much difference is prone to lead to conflict and failure in cooperation. Thus, the compromised culture can be established through negotiation between network members. Cultural diversity is conductive to the knowledge transfer. Due to the difference in mission, function, history and leadership values, there is also difference in the culture of various organizations in the Science and Technology Park, and difference in the organizational systems, standards and management modes. There is a relatively large difference in the culture of the colleges and universities and the enterprises, while the culture of incubator falls in between, of which the incubator can maintain good communication with both parties. The incubator can form a kind of compromised culture between the network members, and form systems and norms that are acceptable for each party, and also retain their own differences. Appropriate difference can form the heterogeneous knowledge, increase the knowledge potential difference and promote the knowledge transfer.

\subsection{Effect and mechanism of the social capital of scientific and technological intermediary on knowledge transfer}

As an indispensable node in the innovative network, the scientific and technological intermediary forms a knowledge transfer network with the enterprises, colleges and universities, scientific research institutions, government and other innovative subjects. The scientific and technological intermediary links up with the relevant innovative subjects to provide ways of knowledge transfer, exchange and diffusion, and also participate in the technology and patent commerciali- 


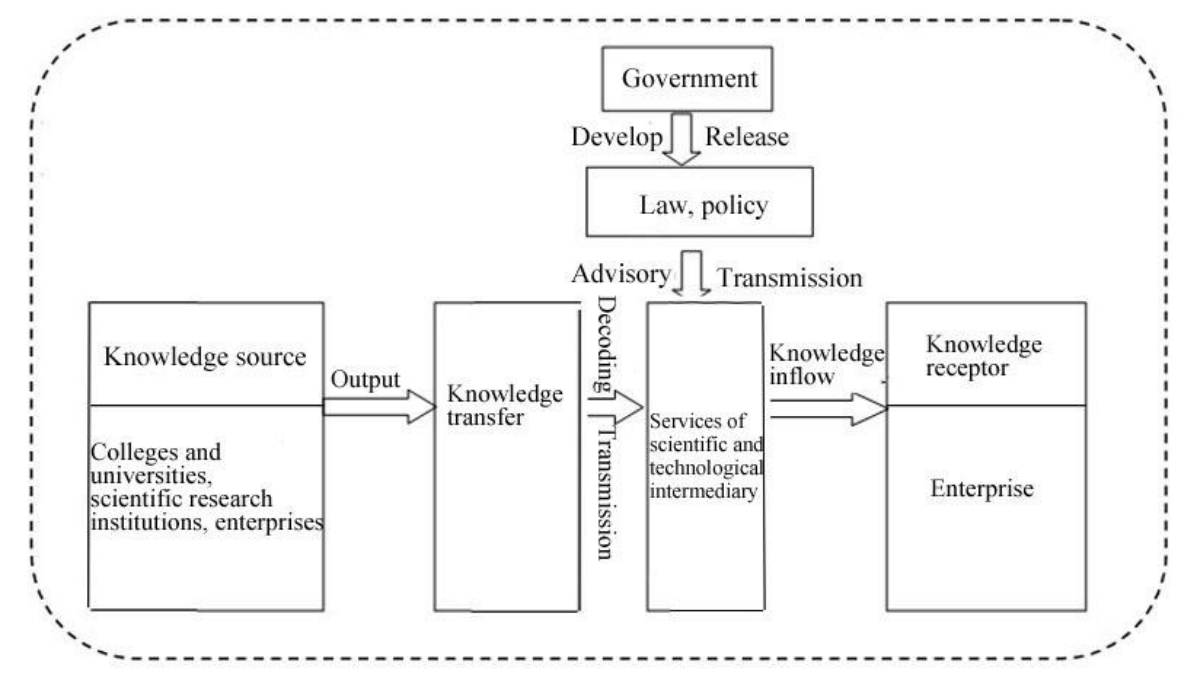

Figure 2. Knowledge transfer model with an intermediary of the scientific and technological intermediary

zation, reduce and eliminate the stickiness of the knowledge transfer, and improve the knowledge transfer performance, which is detailed in Figure 2. The mechanism of the impact of social capital of scientific and technological intermediary and network members on knowledge transfer is different and with their own characteristics.

\subsubsection{Social capital of the scientific and technological intermediary and government}

The incubator and government in the Science and Technology Park have more interaction. On one hand, the incubator transfers the talent, information, finance, tax incentives and other messages to the enterprise; on the other hand, the scientific and technological intermediary transfers the enterprise demand and information of the technology market to the government sector, and provides the basis for government decisions. Good relationship between the incubator and the government is also conductive to their own development and improving the service capabilities of knowledge transfer. The survey finds that the social capital of the incubator and government plays a positive facilitation role in the knowledge transfer opportunity and transfer motivation with less impact on the transfer capacity, because the industrial planning of the government sector plays a leading role in the enterprise development, thereby affecting the development direction of the enterprise products and technology, and searching for new transfer opportunities for the scientific research achievements of the colleges and universities and the scientific research institutions; the support of the government on the talent, information, fiscal taxation and other aspects may increase the knowledge transfer revenues of both parties and promote their enthusiasm about the knowledge transfer, but it has a limited impact on the capacity that both parties to transfer.

\subsubsection{Social capital of the scientific and technologi} cal intermediary and knowledge sources

As the knowledge-produced party and the output party, the knowledge sources include the colleges and universities, scientific research institutions and enterprises. The incubators must clearly understand the scientific research achievements of the knowledge source, and make judgment of its innovation, technical content and commercial prospects and help decision-making of enterprise, so as to rapidly link up with the technology production and technology application, and accelerate transformation of technological achievements into the market. On the contrary, the incubator also conveys the demand information obtained by the enterprise to the knowledge sources, and carries out targeted research and development according to the needs of enterprises, so as to solve technical problems of the enterprises. The survey finds that the social capital of the scientific and technological intermediary and the knowledge source plays a positive role in the knowledge transfer opportunity, transfer motivation and transfer capacity. The incubator adopts its own information and network advantages to search suitable demander for the scientific research achievements, which greatly increases the knowledge transfer opportunities; the trust of the knowledge source toward the incubator and the shared vision reduce the knowledge transfer risks and enhance the transfer motivation; based on the enterprise demand, the incubator proposes clear requirements and recommendations of realization approach for the knowledge sources, so as to improve the knowledge transfer capacity. 


\subsubsection{Social capital of the scientific and technologi- cal intermediary and the enterprise}

The enterprise is the main subject of innovation. Only when the scientific research achievements are $a b$ sorbed, utilized and transformed into productivity by the enterprises can the knowledge transfer be completed. The enterprises often do not know the technology is which kind and how to find appropriate technology to solve technical problems. The incubators can use their technical expertise and a large number of accumulated information resources to rapidly find technical solutions for the enterprises and increase opportunities for knowledge transfer; on the other hand, the incubators can also help enterprises to do technical research, search for technical talents, improve the public service platform of the technology, and improve the knowledge absorption and transformation capacity of the enterprises. There is a high credibility level between the incubators and the incubated enterprises. The enterprises have more trust toward the technical information recommended by the incubators and are willing to accept the proposals of the incubators, thus enhancing the knowledge transfer motivation of the enterprise.

\section{CONCLUSION}

Through the theory construction and open-depth interviews, this research finds that the network relations in the structural dimension of social capital of scientific and technological intermediary are relatively close, which play a role as a "hub" of social capital link in the network; the network has a better density and connectivity, which creates a good environment for knowledge transfer; the stability of network is the best in colleges and universities, better in the scientific research institutions and incubators, and the worst in the enterprises. The credibility in the relationship dimension is out of balance in the network, the highest between the incubators and the government and enterprises, higher in colleges and universities, and the worst in the scientific research institutes. There are differences in the vision of network organization members, which are mainly reflected in the attitude of transformation of scientific research achievement, and there are differences in the shared culture. The scientific and technological intermediary can form compromised culture in the network, and moderate cultural diversity is helpful for knowledge transfer. The research on the relation between the social capital of scientific and technological intermediary and the knowledge transfer finds that the social capital related to government can positively facilitate opportunity and motivation of knowledge transfer but have less impact on the knowledge transfer capacity; social capital related to the knowledge source and corporations all have positive impact on aforementioned three factors.

\section{ACKNOWLEDGEMENT}

This paper is financially supported by the Key Project of Philosophy and Social Science Research in Colleges and Universities in Jiangsu Province.

(No. 2013SJD630120)

\section{REFERENCES}

[1] Jan Fagerberg, David C. Mowery \& Richard R Nelson. 2006. The Oxford Handbook of Innovation. Oxford University Press. pp. 57-82.

[2] Cummings, J.L. \& Teng B. S. 2003. Transferring R\&D knowledge: the key factors affecting knowledge transfer success. Journal of Engineering and Technology Management, 20(1): 39-68.

[3] Jeremy Howells. 2006. Intermediation and the role of intermediaries in innovation. Research Policy, (35): 715-728.

[4] Heidrun C. Hoppe \& Emre Ozdenoren. 2005. Intermediation in innovation. International Journal of Industrial Organization, (23): 483-503.

[5] Laursen K, Masciarelli F, \& Prencipe A. 2012. Regions matter: How localized social capital affects innovation and external knowledge acquisition. Organization Science, 23 (1): 177 - 193.

[6] Wei Ying \& Wang Yun. 2015. Multilevel research overview of corporate social capital and knowledge transfer. Scientific Research Management, (7): 154-160.

[7] Levine S.S \& Prietula M J. 2012. How knowledge transfer impacts performance: A multilevel model of benefits and liabilities. Organization Science, 23(6): 1748-1766.

[8] Vlad Rosca. 2014. A Model for Eliciting Expert Knowledge into Sports-Specific Knowledge Management Systems. Review of International Comparative Management, (15): 57-68.

[9] Smedlund A. 2006. The roles of intermediaries in a regional knowledge system. Journal of Intellectual Capital, (7): 204-220.

[10] Inkpen, Andrew C. \& Tsang Eric W. K. 2005. Social capital, networks, and knowledge transfer. Academy of Management Review, 30(1): 146-165.

[11] Li Yanhua \& Song Fuye. 2007. Impact analysis of the enterprise's external social capital on knowledge transfer between enterprises. Statistics and Decision, 249(21): 179-182.

[12] Yli-Renko. 2001. Social Capital, Knowledge acquisition, and knowledge exploitation in young technology based firms. Strategic Management Journal, 22(6): 587- 617.

[13] Reiche. 2012. Knowledge Benefits of Social Capital upon Repatriation: A Longitudinal Study of International Assignees. Management Studies, (14): 1-26.

[14] Enăchescu, V.A. \& Damasaru, C. 2013. Innovation and creativity in human resource management. Why should we change the way we teach our students? Review of International Comparative Management, (14): 644-653.

[15] Zhang Ming \& Wang Qi. 2014. Construction on framework of standardization system for entrepreneurship services in science and technology incubator. Science and Technology Management Research, (01): 123-128.

[16] Wu Xiaoxia \& Zhou Jian. 2006. Conditions of social capital into knowledge transfer. Future and Development, (11): 40-43. 